\title{
Controlling carbohydrate induced laminitis in horses
}

\author{
JB Rowe 1, MJ Lees 1, DW Pethick 2, K Colbourne 2, CC Pollitt 3 \\ 'Department of Animal Science, University of New England, Armidale NSW 2351; \\ 2School of Veterinary Studies, Murdoch University, Western Australia $6150 ;{ }^{3}$ Companion Animal \\ Medicine and Surgery Department, The University of Queensland, St Lucia 4072, Australia
}

Horses consuming large quantities of rapidly fermentable carbohydrate in the form of starch or sugars may develop laminitis. The first step in the development of this condition is almost certainly severe acidosis associated with reduced volatile fatty acid production and the uncontrolled accumulation of lactic acid. The risk of this fermentation pattern developing can be reduced or eliminated by controlling the gram positive bacteria such as Streptococcus bovis and Lactobacillus $s p$. which are primarily responsible for production of lactic acid at low $\mathrm{pH}$ during anaerobic fermentation within the gut. FounderguardTM is the formulation of virginiamycin for use in horses and is designed to deliver active compound to the hindgut and mix with caecal digesta. Two experiments were conducted to demonstrate that Founderguard ${ }^{T M}$ provided good protection against the development of laminitis provided that it is administered prior to the carbohydrate challenge.

Twenty one horses were used, eight control animals, eight treated with Founderguard $1 \mathrm{M}$ prophylactically for three days before carbohydrate challenge and five treated with Founderguard ${ }^{\mathrm{T} M}$ therapeutically six hours after the carbohydrate challenge. All horses were dosed with ground wheat ( $12 \mathrm{~g} / \mathrm{kg}$ liveweight) prepared as a slurry and pumped into the stomach using a model similar to that of Garner et al (1975, Am J Vet Res, 36, 441). This was given in two equal amounts with an interval of 6 hours between doses. Samples of blood were taken at eight hour intervals for analysis of D-lactic acid and blood gases (the table shows lowest $\mathrm{pH}$ and highest lactate values during the $48 \mathrm{~h}$ period). All animals were slaughtered $48 \mathrm{~h}$ after the first dose of wheat. Hoof sections were taken from the middorsal hoof wall and preserved for histological examination. Four categories of histological damage were described as follows: (Score 1) normal, no visible lesions ; (Score 2) mild changes at the tips of the primary epidermal lamellae (PEL); (Score 3) changes at the tips of the PEL and changes in between the PEL ; (Score 4) changes at the tips of the PEL, in between the PEL and changes between the secondary epidermal lamellae.

Animals treated prophylactically with Founderguard ${ }^{\mathrm{TM}}$ had lower $(\mathrm{P}<0.01)$ blood $\mathrm{D}$ lactate (from gut microbes) and maintained a higher $(P<0.05)$ blood $\mathrm{pH}$ than the control animals or those treated after administration of the wheat. None of the animals treated prophylactically with Founderguard ${ }^{\top M}$ showed clinical signs of lameness compared to approximately $75 \%$ of those in the control and therapeutic treatment groups. There was a significant correlation between clinical lameness and histological diagnosis $\left(\mathrm{R}^{2}=0.86\right)$. It was concluded that by preventing lactic acidosis in the hindgut, Founderguard ${ }^{\mathrm{T}} \mathrm{M}$ reduced the risk of laminitis. Administration of FounderguardTM after carbohydrate challenge was not effective in controlling acidosis or laminitis.

\begin{tabular}{|c|c|c|c|c|c|c|c|c|c|}
\hline \multirow[t]{2}{*}{ Treatment } & \multirow[t]{2}{*}{$\mathrm{n}$} & \multicolumn{2}{|c|}{ Blood D-lactate } & \multicolumn{2}{|c|}{ Blood pH } & \multicolumn{2}{|c|}{ Faecal pH } & \multicolumn{2}{|c|}{ Histology } \\
\hline & & Mean & s.e. & Mean & s.e. & Mean & s.e. & Mean & s.e \\
\hline & 8 & 0.81 & 0.267 & 7.2 & 0.018 & 5.69 & 0.144 & 1.05 & 0.384 \\
\hline & 5 & 0.29 & 0.135 & 7.25 & 0.017 & 5.55 & 0.150 & 1.00 & 0.472 \\
\hline Prophylactic & 8 & 0.08 & 0.022 & 7.32 & 0.012 & 6.40 & 0.078 & 0.16 & 0.105 \\
\hline
\end{tabular}

